\title{
ADVANTAGES AND LIMITATIONS OF THE OBSERVATIONAL METHOD IN APPLIED SOIL MECHANICS
}

\author{
R. B. PECK, C.E., D.C.E.*
}

\begin{abstract}
SYNOPSIS
The observational method, used so successfully by Terzaghi in applied soil mechanics, often permits maximum economy and assurance of safety, provided the design can be modified as construction progresses. The cssential features of the method are set forth and examples are given of its application.

The method is not without its pitfalls and limitations. It should not be used unless the designer has in mind a plan of action for every unfavourable situation that might be disclosed by the observations. The observations must be reliable, must reveal the significant phenomena, and must be so reported as to encourage prompt action. The possibility of progressive failure may introduce a serious elcment of uncertainty.

In spite of the limitations, the potential for savings of time and money without sacrifice of safety is so great that every engineer who deals with applied soil mechanics needs to be informed of its principal features.

La méthode d'observation, utilisée avec tant de succès par l'erzaghi pour la mécanique appliquée des sols, permet souvent des économies maximum et l'assurance de la sécurité, à condition que la conception puisse être modifiée à mesure que la construction avance. Les caractéristiques essentielles de la méthode sont exposées et des exemples de son application sont fournis.

La méthode présente cependant des embûches et les restrictions. Elle ne doit pas être utilisée tant que le constructeur n'a pas à l'esprit un plan d'action qui réponde à chaque situation contraire qui pourrait être révélée par les observations. Les observations doivent être sûres, doivent révéler les phénomènes significatifs, et doivent faire l'objet de rapports tels qu'ils encouragent une mis à exécution rapide. La possibilité d'échecs progressifs peut introduire un sérieux élément d'incertitude.

Malgré les restrictions, les possibilités d'une économie de temps et d'argent sans faire des sacrifices portant sur la sécurité sont si importantes que chaque ingénieur qui s'occupe de la mécanique appliquée des sols doit être au courant de ses principales caractéristiques.
\end{abstract}

\section{INTRODUCTION}

Observational methods have always been used by engineers working in the fields now included in applied soil mechanics, but 'the observational method' is a term having a specific restricted meaning. In its complete and ultimate form the observational method provides a distinct and possibly novel approach to design. I believe we owe its formulation and development as a systematic procedure to Karl Terzaghi.

During the five years in which Soil mechanics in engineering practice was being written, Dr Terzaghi and I experienced the greatest of difficulties with Part C, which dealt with applied soil mechanics. These difficulties came as an unpleasant surprise, because our consuming interest in the practical applications of our subject had induced us to believe that dealing with applied soil mechanics would be the easiest portion of our task. Gradually we realized that Terzaghi's enormous experience had not led him consciously to a deliberate methodology in solving his problems; each problem was attacked as a new entity. Indeed, early in our association he advised me that on every new job I should start without any preconceptions and that it would be well to get all the facts by vigorous probing, quite as if soil mechanics did not exist, before attempting to make any interpretations.

Out of the necessity for writing a book that should contain a consistent method of attack on practical problems, Terzaghi began deliberately to examine and reflect on his instinctively developed methods. He made little progress until the chapters on piping and dam foundations. Here the unavoidable shortcomings in knowledge of the subsurface conditions

* Professor of Foundation Engineering, University of Illinois. 
and their influence on the porewater pressures drew his attention to the necessity for a substantial element of empiricism in design, and he realized the undercurrent of observation common to all his work. He then so quickly organized his conceptions that in 1945 he wrote, for one version of the Introduction to the book:

'In the engineering for such works as large foundations, tunnels, cuts, or earth dams, a vast amount of effort and labor goes into securing only roughly approximate values for the physical constants that appear in the equations. Many variables, such as the degree of continuity of important strata or the pressure conditions in the water contained in the soils, remain unknown. Therefore, the results of computations are not more than working hypotheses, subject to confirmation or modification during construction.

'In the past, only two methods have been used for coping with the inevitable uncertainties: either to adopt an excessive factor of safety, or else to make assumptions in accordance with general, average experience. The designer who has used the latter procedure has usually not suspected that he was actually taking a chance. Yet, on account of the widespread use of the method, no year has passed without several major accidents. It is more than mere coincidence that most of the failures have been due to the unanticipated action of water, because the behavior of water depends, more than on anything else, on minor geological details that are unknown.

"The first method is wasteful; the second is dangerous. Soil mechanics, as we understand it today, provides a third method which could be called the experimental method. The procedure is as follows: Base the design on whatever information can be secured. Make a detailed inventory of all the possible differences between reality and the assumptions. Then compute, on the basis of the original assumptions, various quantities that can be measured in the field. For instance, if assumptions have been made regarding pressure in the water beneath a structure, compute the pressure at various easily accessible points, measure it, and compare the results with the forecast. Or, if assumptions have been made regarding stress-deformation properties, compute displacements, measure them, and make a similar comparison. On the basis of the results of such measurements, gradually close the gaps in knowledge and, if necessary, modify the design during construction.

'Soil mechanics provides us with the knowledge required for practical application of this "learn-as-you-go" method."

To save space, this was replaced by another, shorter introduction in the published book. Statements of comparable clarity did not appear until about 1960 , when Bjerrum so remark ably caught the essence of Terzaghi's method of working in the Anniversary Volume (Bjerrum et al., 1960), and when Terzaghi himself devoted attention to the method while he discussed the past and future of applied soil mechanics (Terzaghi, 1961). The latter statements were more complete and detailed than the one quoted here.

In Terzaghi's hands the observational procedure led to significant and even spectacular successes, yet I have the impression that such consistent and successful use has not been the experience of many other engineers. This Paper examines whether this impression is correct and, if so, why Terzaghi was so notably successful. Can the conditions for successful use of the method be defined? Are there conditions under which the observational method cannot or should not be used?

To the last question at least one categorical answer can be given. If the character of the project is such that the design cannot be altered during construction, the method is

1 Terzaghi's original drafts were in a somewhat cryptic, abbreviated form. I have taken the liberty of editing his notes in accordance with the procedures followed in preparation of the final manuscript of the book as published. 
inapplicable. Otherwise, it may have the potential for great savings in time or money, or for providing needed assurance of complete safety. The possibilities for obtaining these attractive benefits are worth considering.

\section{REVTEW OF METHOD}

In brief, the complete application of the method embodies the following ingredients.

(a) Exploration sufficient to establish at least the general nature, pattern and properties of the deposits, but not necessarily in detail.

(b) Assessment of the most probable conditions and the most unfavourable conceivable deviations from these conditions. In this assessment geology often plays a major rôle.

(c) Establishment of the design based on a working hypothesis of behaviour anticipated under the most probable conditions.

(d) Selection of quantities to be observed as construction proceeds and calculation of their anticipated values on the basis of the working hypothesis.

(e) Calculation of values of the same quantities under the most unfavourable conditions compatible with the available data concerning the subsurface conditions.

(f) Selection in advance of a course of action or modification of design for every foreseeable significant deviation of the observational findings from those predicted on the basis of the working hypothesis.

(g) Measurement of quantities to be observed and evaluation of actual conditions.

(h) Modification of design to suit actual conditions.

The degree to which all these steps can be followed depends on the nature and complexity of the work. We can readily distinguish between projects, on the one hand, in which events have already set the stage for the observational method as being almost the only hope of success, and those, on the other hand, in which use of the method has been envisioned from the inception of the project. Applications of the first type are much the more familiar.

\section{BEST-WAY-OUT APPLICATIONS}

\section{Conditions for suitability of method}

Whenever construction has already started and some unexpected development has occurred, or whenever a failure or accident threatens or has already taken place, an observational procedure may offer the only satisfactory way out of the difficulties. Under these circumstances perhaps most enginecrs would instinctively adopt such a procedure. The mere observation of events, such as the measurements of settlements or lateral movements, often suggests remedial measures that prove to be successful. Yet the results are sometimes disappointing and occasionally disastrous because the observations do not constitute part of a well-considered programme encompassing all the applicable steps in the complete learnas-you-go procedure.

\section{Cleveland Ore Yard}

A classic example of the application of the method is the Republic Steel ore yard in Cleveland, Ohio, well-known to those who have read Terzaghi's report in the Anniversary Volume (Bjerrum et al., 1960). The example is familiar and so only the aspects most significant to this discussion are mentioned: the location, general layout and dimensions of the ore yard had been fixed before Terzaghi came to the job; the exploration was limited to four borings, which were sufficient to establish the likelihood of foundation failure but not to disclose all 
the variability in subsurface conditions; the observational programme was rather elaborate, planned with the greatest of care and conscientiously executed; the results were studied and interpreted without delay, on a weekly or sometimes daily basis; the ore load could at any time or place be held constant, or even rather quickly decreased, if necessary to prevent failure. Thus the maximum possible utilization of the ore yard was assured, but at the same time the possibility of failure was eliminated. Had the actual capacity of the ore yard been less than the requirements of the blast furnace, the steel company would have faced an economic penalty for shipping part of the ore to the furnace by railroad as needed, but they did not face the far greater penalty of a failure of their dock or their loading and storage facilities. In this instance the observational procedure certainly falls into the 'best-wayout' category.

\section{Cape Kennedy Causereay}

A more recent illustration involving quite different physical phenomena concerns a causeway at Cape Kennedy to permit transport of Saturn rockets from the Vertical Assembly Building to one of the launching pads, a distance of about four miles. The rockets, each about as high as a 35-storey building, are transported in a vertical position on a platform carried in turn on four track-type crawlers resembling huge bulldozers. The crawlers operate on a compacted 'limerock' surface about $3 \mathrm{ft}$ thick resting on hydraulically placed uniform fine sand overlying similar natural sand. The general ground surface is only a few feet above sea level.

The first of two such causeways was constructed and used without difficulty except for a few zones of minor settlement where the subsoil contained lenses of clay. Accordingly the second was built like the first, on the basis of preliminary exploratory borings that disclosed similar sands but only minor inclusions of clay. Construction was started while exploratory studies were still being made because of the accelerated pace of the space programme. Most of the studies consisted of dynamic penetration tests similar to the standard penetration test

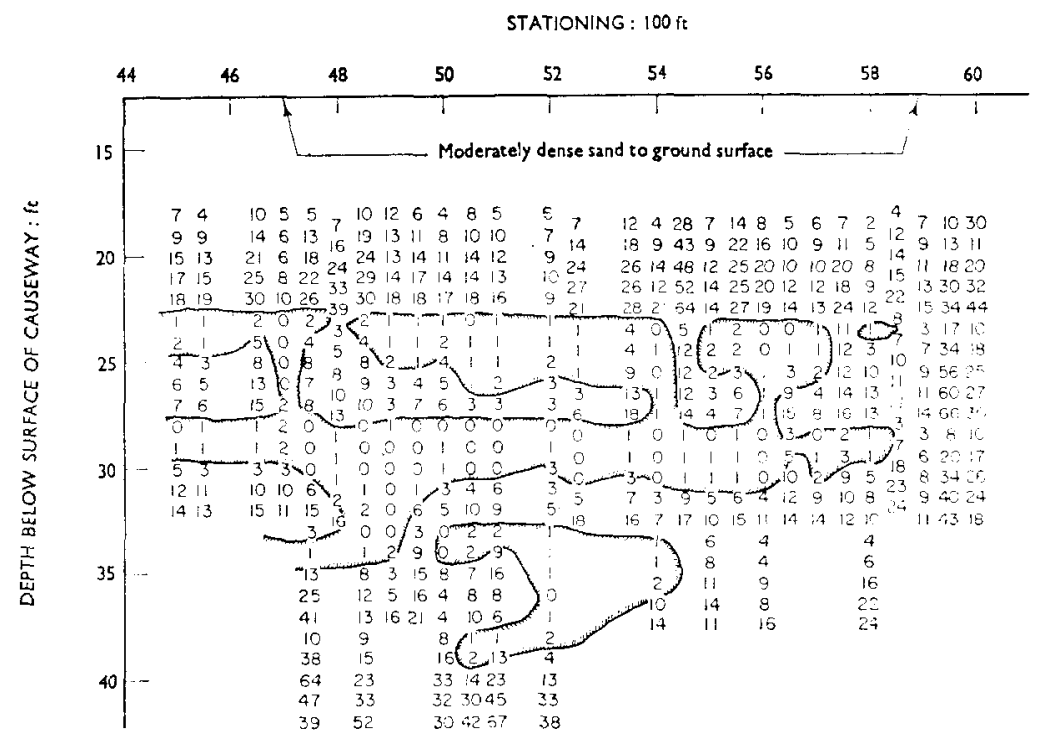

Fig. 1. Penetration resistance record showing zone of extremely loose sand beneath causeway. Numbers indicate blows per foot on two-inch o.d, sampler weighing $300 \mathrm{lb}$ and falling 18 in. 
except that a $300 \mathrm{lb}$ weight was allowed to fall $18 \mathrm{in}$. The number of blows was counted for each foot of penetration. The results disclosed several zones in which the resistance was consistently less than 2 blows/ft. One of these (Fig. 1) near station 52 was much deeper and looser than any that had been encountered beneath the first crawlerway, and suggested the possibility of liquefaction and sudden failure under the passage of the fully loaded transporter. It was concluded that the degree of danger could not be assessed reliably by any known procedure using the results of laboratory tests, but that positive steps were nevertheless required to assure that no accident could possibly lead to overturning the transporter while it was carrying a Saturn vehicle.

Among the positive steps considered were the injection of chemicals to provide stabilization, densification by vibroflotation, removal of the loose sands and their replacement by stable fill, and dewatering or surcharging to produce at least some breakdown of the structure of the loose sand. The great expense of any of these measures made them unattractive but, more important, the time required for the operations would have disrupted the entire Saturn programme. Finally, in the interests of safety, each method would have been applied to many areas where it might not have been needed at all.

An obscrvational proccdurc was worked out that would avoid all the scrious disadvantages of the 'positive' methods and that instead would have several inherent advantages. It would consist essentially of traversing the causeway with the unloaded transporter, and then by the transporter plus larger and larger fractions of the design load. At each stage of loading some alteration of structure of the sand could be expected on account of the shearing stresses induced by the load; any such alteration would be beneficial. The alteration would presumably be accompanied by an increase in porewater pressure. If the pore pressure were to exceed a certain amount liquefaction would develop, but if the maximum pore pressure could be kept below this limiting value the deposit could be progressively densified by successive passages of the transporter and any appropriate fraction of the full load. As the sand was fairly pervious excess pore pressures were thought likely to dissipate rapidly.

Accordingly the following observational devices were set up: settlement reference points at the surface along and beside the entire causeway; settlement observation plates at the top and bottom of the loose zone; slope indicator casings alongside the zone; and porewaterpressure measuring devices (quick-acting and automatically recording) at the upper and lower quarter points in the thickness of the loose sand zone. The unloaded transporter, constituting about one third of the design loading, was slowly advanced over the causeway.

Porewater pressures, equal to about one third of the increase of stress calculated on the basis of the theory of Boussinesq, were observed in the loose sand. These dissipated rapidly whenever the transporter was stopped. A small but significant decrease in thickness was observed in the sand, even after a single passage of the unloaded transporter. These observations were considered favourable because they demonstrated that the structure of the sand could be altered at relatively low loads, if necessary by repeated loadings, and that the rise of pore pressure could be reduced by slowing down the transporter.

At this stage the results were available of studies of the ability of the transporter to carry loads, such as boxes of earth or tanks of water, equal to such fractions as 50 or $75 \%$ of the design load. The studies showed that the required structural modifications could not be made quickly or at reasonable cost. Due to the details of the structural framing of the transporter, the next practical increment of load would be the weight of the launcher-umbilical tower (LUT). The load of transporter plus LUT would constitute roughly $90 \%$ of the design load including the weight of the rocket.

The favourable results with the unloaded transporter were felt to justify the conclusion that it would be safe to subject the causeway to the transporter and LUT, since the transporter could if necessary be made to operate at an extremely slow speed and the porewater 

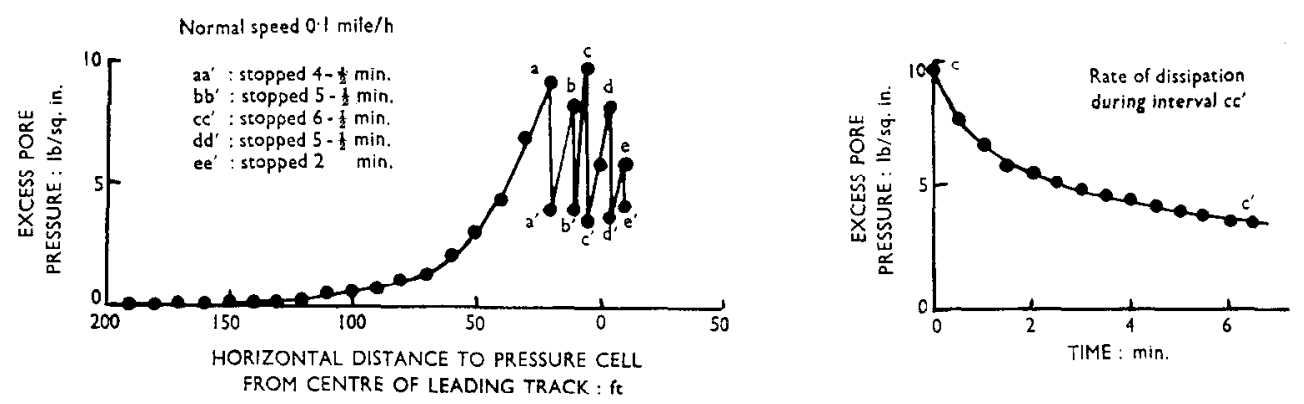

Fig. 2. Typical pore-pressure observations during first passage of transporter and LUT, Saturn causeway. The pressure cell is located at a depth of $19.2 \mathrm{ft}$

pressure thus kept under control. The only drawback appeared to be the possibility that the advance might have to be so slow that the space programme would be delayed. This risk was judged to be slight and was accepted.

It proved possible to control the pore pressure within close tolerances by reasonable adjustments in the rate of advance of the load. Typical results of the observations are shown in Fig. 2. With each passage, densification occurred and in a general way the pore pressure under the next loading was smaller than before. The loosest zones, by now clearly defined by the measured surface settlements, were traversed several times until their behaviour approximated that of the sand beneath satisfactory portions of the causeway. Lateral displacements, indicating gradual shearing distortions of the mass of sand, were clearly shown by the slope indicators. They did not exceed about 1.5 in.

After the combination of field measurements and 'proof testing', the causeway was felt to be conditioned to the point that it would be safe to operate the fully loaded transporter at its normal speed, with the only restriction that the pore pressures should be observed and controlled. If these pressures should exceed a predetermined amount that had in fact already been exceeded during the previous tests, the rate of advance of the transporter should be reduced as necessary.

This programme was followed with the greatest success. No restrictions on rate of travel were found necessary in routine operation of the transporter, and with each passage of the load the safety improved.

\section{AB INITIO APPLICATIONS}

\section{Harris Trust excavation support}

Although the observational method often offers the best way out of difficulties that have already developed, its intended use from the inception of a project offers even more opportunity for imaginative planning and may lead to the best possible design from the points of view of safety, economy and time. ${ }^{2}$ For example, the bracing system for support of the sides of the excavation for the Harris Trust building in Chicago was designed to take advantage of knowledge of the actual conditions at the site. A cross section through the proposed excavation, indicating the levels of bracing as determined by the requirements of the permanent substructure, is shown in Fig. 3(a). The contractor had at his disposal the results of

\footnotetext{
2 One of the earliest and best examples of the use of the method from the beginning of a project was to ensure the verticality of the turbine shafts at the Svir III hydroelectric project (Graftio, 1936; Terzaghi and Peck, 1948). Since Terzaghi was a consultant on the work, it is more than likely that he was responsible for the approach.
} 


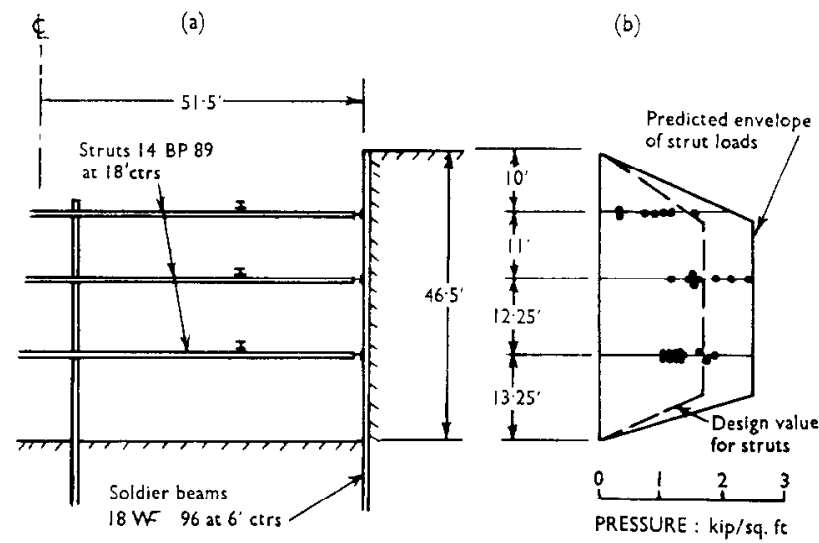

Fig. 3. Braced cut for Harris Bank and Trust Co., Ghicago: (a) Section through cut showing bracing; (b) Comparison of pressures computed from measured strut loads with those used for design and with those predicted from semi-empirical envelope

strut-load observations at several sites in Chicago (Peck, 1943; Wu and Berman, 1953), including those from one of his own recent projects only a block away. The information was available in the form of a trapezoidal diagram (Fig. 3(b)) representing an envelope of all strut loads measured on similar cuts in Chicago.

Design of struts for the new cut could have been based on the trapezoidal diagram with the assurance that no strut in the new system would have been overloaded. However, since the trapezoid is indeed an envelope, most of the struts in any cut would carry loads considerably smaller than those corresponding to the diagram. The contractor proposed to design the struts at a relatively low factor of safety for loads equal to about two-thirds of those predicted by the envelope, or approximately for the average loads corresponding to all the previous measurements. By so doing he found he could achieve considerable economy. To guard against overloading those few struts that might be subjected to loads approaching the ones given by the design envelope, he proposed to measure the axial load in every strut at all significant stages of construction, and to have available for immediate insertion additional struts wherever and whenever indicated. Only three struts had to be supplied in addition to the 39 struts required for the entire project. The cost of these was small compared to the savings, even including the cost of the observations. Not only was the procedure economical, but it provided positive assurance that no strut in the entire system would become overloaded (White, 1958). The details of the bracing system were designed to permit easy insertion of new struts. The use of continuous steel walling and steel struts of $\mathrm{H}$-section satisfied this requirement.

In this example, the planned course of action in the event of higher-than-anticipated strut loads was simply to insert more struts. Even under very unfavourable circumstances the penalty would have becn no more than a moderate increase in cost and a few short delays. In contrast, in the following example the stakes were much higher and the possible penalties much greater, yet the observational procedure proved to be highly successful.

\section{Bay Area transit tunnels}

At one point of the Bay Area Rapid Transit in San Francisco, the traces of two tunnels curve gently from one street to another. As shown in Fig. 4, one of the tunnels barely passes beneath the corner of the basement of an eight-storey reinforced concrete structure supported 


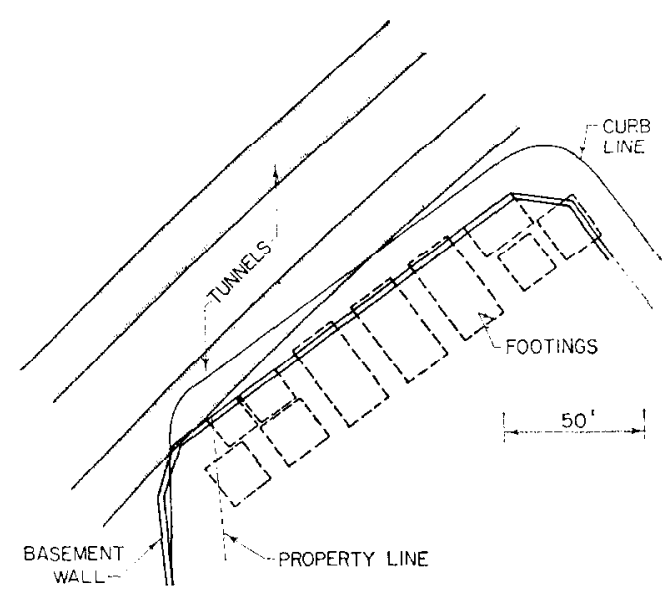

Fig. 4. Plan showing relative positions of building foundations and subway tunnels

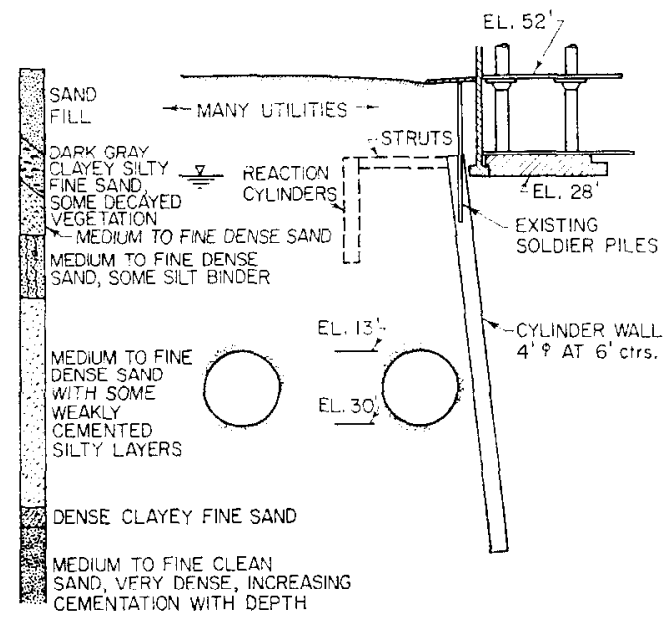

Fig. 5, Proposed cylinder wall for protection of building from movements due to subway construction

on individual and combined spread footings. The building is fully occupied by the owner, who makes active use of the basement space; moreover, it is designed to carry an additional eight storeys, probably to be constructed in the near future.

The location of the tunnels in relation to the structure and the general subsurface conditions is shown in Fig. 5. The sediments located between the elevation of the base of the building and that of the invert of the tunnels consist primarily of fine sands, slightly cohesive in some zones, and apparently very dense as judged by values of the standard penetration test. Above footing level, however, the sand is looser and may be fill. Patches of organic matter are encountered at various depths within and at the bottom of the upper sands, and buried stream-channel deposits at the same levels are known in the vicinity. Hence, lowering the groundwater level in connexion with tunnelling operations was expressly forbidden, in order to prevent settlements of shallow foundations in the neighbourhood. It was believed that the footings of the building were founded just below the organic zones. Settlement of the structure under its own weight was not known, but at the time the building was designed the foundation consultant predicted a further settlement of 2-3 in. when the eight new storeys were added.

Conventional procedure would have called for underpinning before tunnelling because of the importance of the building. Under the circumstances, however, underpinning seemed out of the question. If only the line of footings next to the tunnel were underpinned, and if indeed the additional storeys would later cause several inches of settlement of the remainder of the building, severe damage might result. Furthermore, underpinning would require working either within the basement area, with interference the owner could not tolerate, or beneath the present foundations. The latter alternative would require lowering the groundwater level at least 8-10 ft and would therefore be unacceptable. The permeability of the sand, especially where there was a slight clay content, was too low to permit injection of cement grout or even of chemical grouts. Hence the normal as well as the more exotic methods of underpinning seemed to be unsuitable. 
Many of the engineers associated with the work felt that the settlements at the edge of the structure would be too small to be detrimental, but no applicable experience could be found that would warrant a conclusion that excessive settlements due to tunnelling could not or might not occur. It was agreed that positive assurance had to be provided that the building would not be harmed.

Of the many alternatives studied only one seemed to offer positive assurance. It consisted of a structural wall or frame interposed between the tunnels and the building to shield the building from movements due to the tunnelling. A row of heavily reinforced concrete cylinders (Fig. 5), slightly inclined to meet the required clearances, was to be constructed, one cylinder at a time in slurry-filled holes, to a depth great enough to develop fixity in the dense sand beneath the level of the proposed tunnel. If needed to provide further restraint, the additional cylinders and cross-struts, shown by dashed lines in Fig. 5, could be provided.

The cost of the protective work was estimated at nearly half a million dollars, yet the need was problematical. The observational method was invoked in the following form. The protective work was not included in the tunnel contract but the design was held ready if the need should develop. The tunnel contractor was to start work several thousand feet from the building and advance towards it. Thus his equipment and method of operation could be judged several months before he would reach the critical point, as he traversed materials thought to be similar to those at the building site. Settlement observations would be made on the surface, at subsurface reference points and on buildings as the work progressed. If the tunnelling operation proved to be well-controlled and settlements minimal, the contract for the protective work would not be awarded. On the other hand, if settlements were excessive and could not be controlled, a contract for the protection would be awarded with a completion date before the anticipated arrival of the tunnels. In the remote likelihood that the settlements over the tunnels should at first be so small that the protection would be omitted, but should increase as the tunnels approached the building, the tunnel contract might have to be stopped until the protective work could be done.

The contractor elected to use a mining machine. He did indeed experience several difficulties in the first few hundred feet of his operation, and loss of ground could be observed at the street surface above one tunnel. He soon adjusted to the situation, however, and advanced thereafter with maximum settlements over the centre-line of the tunnels of about $\mathbf{0 . 5} \mathrm{in}$. Much smaller settlements occurred over the edges of the tubes. Consequently no protective works were considered necessary. In fact the building experienced negligible settlement when the tunnel was being constructed in its vicinity.

Had there been a less expensive alternative for protecting the structure, it is likely that it would have been invoked rather than the observational method. The stakes were higher than usual because of the great cost of the cylinder wall. However, the initial quandary did not arise entirely on account of the expense and difficulty of protecting the structure. It was caused also by lack of convincing field data about the actual behaviour of similar ground while being penetrated by similar tunnels. Surprisingly few adequate case histories are on record with respect to the effects of tunnelling in various soils.

The examples given illustrate the great variety of projects to which the observational method can be applied and the room for ingenuity in planning and interpreting the observations. $^{3}$ In all the examples substantial benefits were realized that would have been lost if conventional procedures had been used. Nevertheless the method is not without its pitfalls. A realization of their nature and consequences is a prerequisite to repeated success.

3 The incorporation of test fills or test embankments into a project in such a manner as to permit modification of the design has become widespread practice. The Great Salt Lake Crossing, with its full-scale test fill and extensive observations during construction, is an outstanding example (Casagrande, 1960). 
PITFALLS OF THE OBSERVATIONAL METHOD

\section{Failure to anticipate unfavourable conditions}

Potentially the most serious blunder in applying the observational method is the failure to select in advance appropriate courses of action for all foreseeable deviations of the real conditions, as disclosed by the observations, from those assumed in the design. If the engineer suddenly realizes that the observations show the job to be heading for trouble against which he has no defence, he must reach crucial decisions under the pressures of the moment. If he is very unlucky he may find that there is no adequate solution at all. Had he originally considered all the possibilities, he would have concluded in advance that if certain unfavourable conditions prevailed he would not be able to carry out the design, and he would not have embarked on a design vulnerable to such conditions.

In short the engineer must devise solutions to all problems that could arise under the least favourable of the conditions that will remain undisclosed until the field observations are made. If he cannot solve these hypothetical problems, even if the probability of their occurrence is very low, he must revert to design based on the least favourable conditions. He can then no longer gain the advantages in cost or time associated with the observational method.

\section{Dam over buried valley}

Whether or not one single potential problem can be solved may have a remarkable impact on the cost of a project. Exploration of the site for a low dam in glaciated country disclosed a bedrock valley having the approximate dimensions shown in Fig. 6. The valley fill appeared, on the basis of a few borings made at great expense, to consist of three zones. The uppermost zone was interpreted to be a mixture of sandy and gravelly boulder clay intermixed with talus, very erratic and locally pervious. The middle zone, considerably thicker than the other two, contained three beds of sand, each of grain size smaller than that of the bed above. The lower bed of the middle zone was silty and of lacustrine origin, visibly

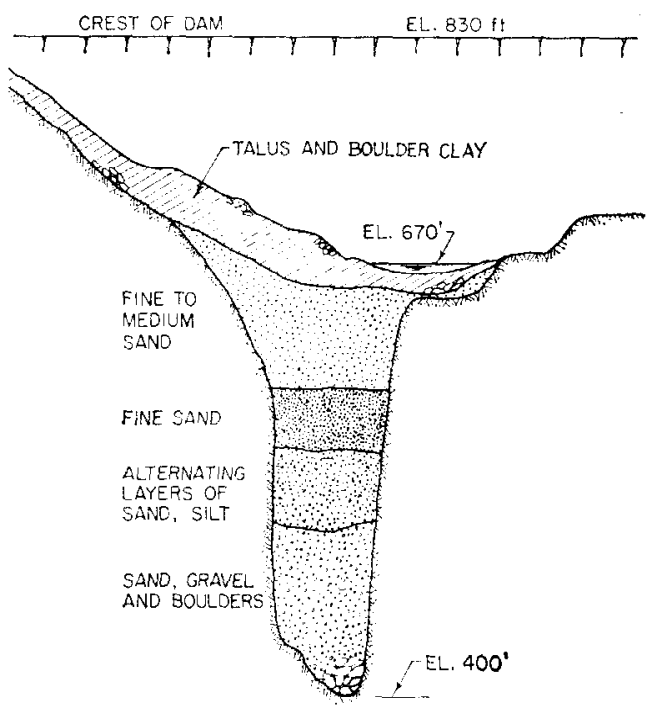

Fig. 6. Section through buried bedrock valley at dam site 
stratified, having low vertical and moderate lateral permeability. The lowest of the three major zones was pervious and appeared to consist of lenses of granular materials, some quite coarse-grained.

A simple pumping test in the lowest deposit demonstrated convincingly that the granular material was enclosed in almost impermeable surroundings, inasmuch as very small pumpage drastically lowered the piezometric levels in the deposit at considerable distances upstream and downstream. The glacial geology of the area indicated that the overlying lacustrine material must have been heavily precompressed by ice. These favourable conditions led to serious consideration of establishing the dam on top of the lacustrine materials without any cut-off through them or the underlying granular soils. The cost would have been substantially lower than that of excavating to rock and constructing a compacted clay cut-off with suitable transitions and filters, back up to the present bed of the river. The saving in time would also have been substantial and could have led to earlier production of marketable power.

Of the various problems to be considered only one defied acceptable solution. Owing to the steepness of the rock walls and of sets of vertical joints parallel to the course of the stream, open cracks or relief joints were likely to be present near the buried rock cliffs. These openings would provide opportunity for flow from upstream to downstream just beyond the highly erodible lacustrine soils. Should there be open joints from other sets intersecting the relief joints, flow patterns could be contemplated under hydraulic gradients that might initiate piping of the soils. Although the probability of such an occurrence seemed low, the possibility could not be dismissed. Detailed pore-pressure observations near the valley wall in the valley fill and in the rock might have disclosed some of the unfavourable situations, although the flow pattern would locally have been very complex and not readily interpretable. Nevertheless, even if the locations of adverse features could be disclosed, no suitable, foolproof means of eliminating the problem could be agreed. The expense of grouting operations and their uncertainty under the prevailing conditions did not seem to justify reliance on injections. For lack of a suitable course of action in this eventuality, the design was abandoned in favour of excavating to the bottom of the buried gorge, examining and treating the rock faces as they actually existed and constructing a complete cut-off. The potential savings of a design in which the water pressures in the lower granular material would be observed and controlled could unfortunately not be realized.

Possibly more detailed and careful study of the patterns of flow into and out of the open joints at the interfaces with the lacustrine soils would have shown that, from a hydraulic point of view, the unfavourable flow patterns could not actually be as detrimental as was assumed; in other words, more complete knowledge of the phenomena involved, perhaps supplemented with more detailed exploratory work, might have justified leaving the lacustrine soils in place. The applicability of the observational method undoubtedly increases with increasing knowledge and ingenuity of the engineer. Nevertheless there will always be projects in which no advantage can be taken of the hoped-for savings of the observational method because no suitable course of action can be devised for some anticipated eventuality.

Furthermore, the selected courses of action must be realistic ones. It might be reassuring to the owner to be told that if the hydraulic conditions in the dam just described were found to be unfavourable, they could be corrected 'by grouting'. All too often similar statements are made, more in hope than in realistic appraisal. If the statements are too optimistic the safety of the structure cannot be assured.

\section{Choice of significant observations}

Of equal importance to that of devising adequate courses of action for all eventualities is making the right observations. The selection of proper quantities to observe and measure 
requires a feel for the significant physical phenomena governing the behaviour of the project during construction and after completion. On some projects the phenomena are well known and the obscrvations are required merely to evaluate the degree to which they influence behaviour. For example, on sand drain jobs pore-pressure dissipation is undoubtedly understood by the engineer to be the phenomenon of greatest significance in achieving the purposes of the installation. The rate at which it occurs, however, cannot be forecast reliably enough to permit predetermining the rate of surcharge loading, and observations are required for construction control. There is little risk, at least on routine sand drain jobs, that some unsuspected phenomenon may prove to govern the behaviour.

\section{Subsidence of chemical plant}

If the governing phenomena are complex, or are not yet appreciated, the engineer may measure the wrong quantities altogether and may come to dangerously incorrect conclusions. The possibility of serious crror for this reason was harshly impressed on me more than twenty years ago. In those days, in addition to his regular duties at Harvard, Terzaghi held the title of Lecturer and Research Consultant at the University of Illinois. He conscientiously spent most of a week each semester in Urbana, lecturing and discussing rccent devclopments with students and staff. As part of the routine he took to his hotel with him whatever reports I had written on jobs since his last visit, and the following day always cross-examined me in the greatest detail.

On one of these occasions I had handed him a report on subsidences of a large area occupied by a chemical plant. The site was underlain by a thin surficial deposit of sand with occasional organic inclusions, followed by some $50 \mathrm{ft}$ of soft, normally loaded clay which rested in turn on limestone bedrock. The upper part of the limestone was known to be pervious and in the early 1900 s to have contained water at a piezometric level about $20 \mathrm{ft}$ above the present ground surface.

Widespread irregular subsidences had occurred at the site over many years. They had provoked little attention until the arrival of a new chief engineer. As he sat in his newly painted office, he observed the appearance and widening of cracks in the walls and set out to investigate their cause.

It developed that shortly after 1900 the chemical plant began to derive its basic raw material, sodium chloride, by solution of beds of salt at depths from 800-1100 ft. Water from a nearby river was injected into wells, became saturated and was withdrawn. In some of the older wells, however, no river water was furnished. The outer casings of the brine wells were simply perforated, or had deteriorated, in the pervious upper part of the limestone and the groundwater in the limestone aquifer flowed freely into the wells. The piezometric levels in the limestone were accordingly reduced by about $80 \mathrm{ft}$. I concluded that the reduction of piezometric levels at the base of the clay had induced consolidation of the soft overlying materials. Calculations of settlement on the basis of laboratory values of the compression index of the clays indicated that the ultimate settlements should be of the order of 3-5 ft, values that agreed well with those deduced from the settlement observations. The agreement was so satisfactory that I considered all the observed settlement to be accounted for, and felt confidence in the explanation.

I still recall vividly the conversation when I called for Terzaghi the morning after he read the report:

'Now, about that report on the subsidence ...'

'Yes?'

'I think you have missed the boat. .. ' He paused. 'It is obvious that the settlement is in the bedrock.'

'But that is impossible. The bedrock is too thick,' I protested. 
'How do you know it is impossible? You didn't establish any reference points at the surface of the bedrock, did you?'

'No, but the general magnitudes of the observed settlements agreed with the computed ones.'

'Didn't you notice that the real pattern of differential settlement is much more abrupt and erratic than the computed one?'

'Yes, but I think this difference is caused by the presence of erratic, compressible organic deposits near the ground surface.'

'What is the evidence? You have forced the evidence to fil your preconceived notions,' he accused.

Indeed I had, as I gradually and painfully learned. Together, Terzaghi and I embarked on an excursion, to last more than a decade, into the use of the observational method, this time not in soil mechanics but in engineering geology. Eventually the study demonstrated conclusively that subsidence of the rock strata was laking place above solution cavities, and it was found necessary to develop new brine fields not located beneath the plant areas. Had my original conclusion been believed, it is quite likely that a serious accident, such as a surface sinkhole, might have occurred with possible destruction of life and property.

Terzaghi in his broad experience had encountered similar situations before; I had not. My observational programme was inadequate to disclose a phenomenon I did not even suspect. Yet my lack of experience was not the only reason for failure: I had also failed to examine all the available evidence with an open mind.

Careful attention to detail of observations intended to support my working hypothesis might have thrown doubt on its validity. Essentially, however, preoccupation with the wrong phenomenon succeeded in creating a blind spot with respect to the significant one. The user of the observational method must constantly be aware of this possibility.

\section{Influence of progressive failure}

The presence of brittle elements in a resisting mass may, if not appreciated, lead to failure in spite of the use of the observational method. The brittle elements may consist of stiff layers of cohesive soil which may develop high resistance at small strain, but may suddenly fail and transfer their load to weaker, more deformable layers. Progressive failure may thus be initiated before the movements are observed. In most slides detectable movements of the softer soils occur before the stiff units fail and careful observation would disclose the possibility of failure, but in some instances detection may require keen insight into the possible behaviour and the most precise measurements.

\section{Neighbouring grain elevators}

The contrasting behaviour of two similar grain elevators, supported by timber piles extending through similar subsoils, is illustrated in Fig. 7, in which the lateral movements of the elevators are plotted as a function of time. Each elevator was acted on by a substantial lateral force caused by filling on the land side. The large deflexion of the elevator represented by curve $a$ would suggest approaching failure, whereas the slight deflexion experienced in thirty years might easily be taken to indicate superior behaviour of the other elevator, curve $b$. However, elevator $b$ failed suddenly, at a much smaller previous deflexion than $a$. The following explanation is conjectural, but in accordance with the known facts. It was found that both foundations contained batter piles. There were so few batter piles beneath $a$ that they could have exerted only negligible resistance and may even have failed at an early date. It is likely that resistance to lateral deflexion was developed wholly by slowly deforming the block of soil in which the vertical piles were embedded. The other 


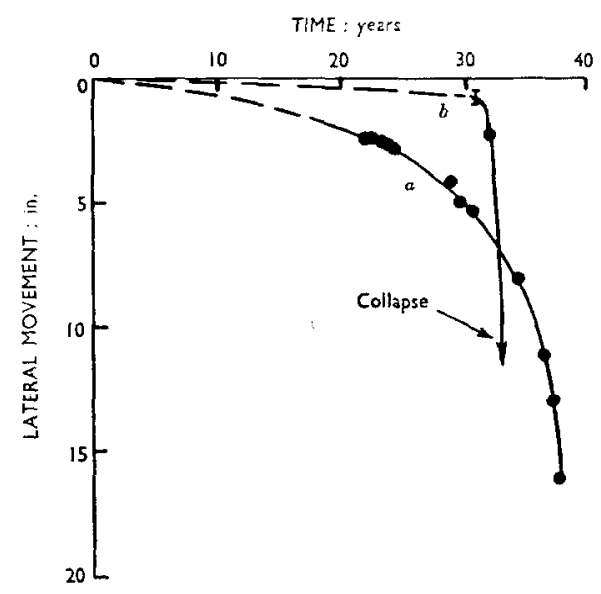

Fig. 7. Relation between lateral movement and time for two pile-supported grain elevators above similar clay foundations

foundation contained a larger proportion of batter piles capable of resisting the lateral loads by axial compression at a small factor of safety and at small lateral deflexion. As a result of a minor accident a few of the piles were damaged and transferred their lateral load to the neighbouring batter piles. These piles, then overloaded, broke one after another. The lateral load was then thrown rapidly on to the vertical piles. The surrounding soil, in which high pore pressures were probably generated, could not sustain the rapidly applied lateral loading and failed. As the fundamental difference in behaviour associated with the seemingly inconsequential difference in the number of batter piles in the two foundations had not been anticipated, the owners of elevator $b$ were unfortunately reassured by its negligible deflexion for many years. It may be concluded that the engineer who plans an observational programme or undertakes to interpret data already available must have reliable knowledge of the conditions pertinent to the problem-in this instance, the layout and type of batter piles-and must take into account all possible modes of behaviour or failure, otherwise one of the underestimated, discounted or unknown modes may develop without being noticed because no suitable observations have been devised for detecting it.

\section{Reliability}

\section{OBSERVATIONS THEMSELVES}

It is not the purpose of this Paper to discuss specific observational techniques, although a few generalities may be justified because of their relevance to the methodology and applicability of the observational procedure.

It is, of course, essential that the quantities to be observed should reflect the phenomena that will actually govern the behaviour of the works to be constructed. As shown, a mistaken preconception of the nature of a problem may lead to the omission of observations of types that would have disclosed the real reasons for concern.

The results of the observations must be reliable. If we have adopted the observational method as the final basis for design and if the observations fail, our plight may well be desperate. Regrettably, far less thought is usually put into the planning of the observations than is needed. Far too much dependence is placed on reports of the successful performance of instruments that are in reality almost untried under field conditions or have actually failed or given erroneous results in most installations. To a large extent this unfortunate 
situation arises because those who see the need for the measurements and who plan the programme are not themselves personally experienced in installing, observing and maintaining various types of instruments under a variety of conditions and for a number of years. They cannot believe that the bad luck occasionally reported is likely to be the rule rather than the exception, or that the latest malfunction of an instrument on someone else's job would be just as likely to occur on theirs. Nor can they believe that contractors and even resident engineers may not share their view of the importance of the observations and may not exercise the devotion needed to protect and observe the installations. Whoever plans an installation of any complexity will need all the skills that can be developed only by years of experience in actually installing and observing field measuring equipment.

I am well aware that there are few people who can claim years of personal experience with field observations, and I am also aware that the shortage of such people is a handicap to those who would use the observational method. To meet the need, there is emerging a group of specialists in field installations and the needed instrumentation. Such specialists have a constructive rôle to play in applied soil mechanics.

On the other hand, it would be most unrealistic to conclude that all applications of the observational method require specialists and sophisticated instruments. On many jobs simple observations with transit and level, and determination of water levels in open standpipes are entirely adequate and can and should be carried out by the men closest to the job. Indeed, observations are often far more elaborate and costly than necessary, sometimes to the detriment of the project. There is unquestionably a place for the 'quick and dirty' test.

\section{Crude pumping test}

At the dam site shown in Fig. 6, the basic design hinged on whether a cut-off was necessary through the coarse alluvium in the bottom of the old bedrock channel. There was a reasonable probability that the overlying lacustrine materials were continuous and were effectively sealed to the rock at the sides. To investigate these conditions a pumping test was to be made in the alluvium. Piezometers were installed in drill holes appropriately located in the various formations as well as in the bedrock, and drilling of a pumping well was started. A detailed schedule of pumping and of making observations was developed to permit reliable interpretation of the results.

Unfortunately the contractor for the pumping well invested an unusual amount of time in constructing a drilling platform for his operations, and subsequently found his drilling equipment was inadequate to cope with the many boulders and rock fragments encountered. Finally, only a few days before a tentative decision on the design had to be reached, a new drilling contractor was engaged who was able to advance the hole a few feet into the gravel and to pump for about two hours by means of an air lift. The rate of discharge was only $30 \mathrm{gal} / \mathrm{min}$, but the piezometric level in the alluvium dropped $80 \mathrm{ft}$ at a distance of $100 \mathrm{ft}$ from the pumping well. Even at a distance of $650 \mathrm{ft}$ the drawdown in the underlying jointed rock was about $20 \mathrm{ft}$. This crude information was entirely adequate to establish for practical purposes the hydraulic independence of the alluvium from the water in the river, and fully justified serious consideration of a design incorporating pressure relief wells rather than a complete cut-off. Subsequent more refined check tests merely reaffirmed the findings from the cruder procedure.

\section{Reports on field observations}

However the field observations are made and whether they are elaborate and precise or 'quick and dirty', the results are useful only if they are displayed promptly in such a manner as to show quickly and clearly the essential features. The reports containing the results 
should be regarded as working documents, issued whenever the information needs to be brought up to date. Unfortunately there is a tendency to accumulate data until an elaborate, fully documented final report can be prepared. Such a report may become a goal in itself. Not infrequently less thought goes into the significance of the data with respect to design and behaviour than into the mechanics of production of the document, and observations are made to fill gaps in a table rather than to provide understanding when significant events occur. This trend is in sharp contrast to the many searching and fruitful inquiries Terzaghi pursued into the meaning of even chance observations.

\section{CONCLUSIONS}

It has been shown that the observational method has its limitations and drawbacks. It can be used only if the design can be altered during construction. This essential feature often introduces complications into contractual relations. If the construction contract exists before the observational procedure is applied, the owner's bill may go up even though the actual cost of performing the work may go down.

Often the procedure is adopted to provide assurance that enough time has passed to achieve some desirable end, such as the avoiding of a certain amount of settlement or the gaining of a required shearing resistance. The time required for these ends is not reliably predictable, otherwise the observational procedure would not be used. The possibility of having to slow down construction is a drawback inherent in the method. It may cause financial loss and may even make the financing for the project difficult to arrange. Finally, in some instances the probability of being faced with the most unfavourable conditions may be so high that use of the procedure is not worth the cost. At Cheakamus Dam, for instance, Terzaghi felt obliged to base the design on the worst conceivable conditions rather than on average anticipated conditions (Bjerrum et al., 1960).

In spite of these drawbacks the method offers many possibilities of spectacular savings of time or money, and it can provide the assurance of safe construction without the financial penalty attached to excessive safety. Hence anyone who practises the application of soil mechanics needs to be fully aware of the potential value of the observational method and needs to understand the prerequisites for its success.

There is no doubt that the full value of the method cannot be realized unless the engineer is thoroughly conversant with his problem, makes continuous alterations of designs and procedures as the information is obtained and has the authority to act quickly upon his decisions and conclusions. These requirements would seem to favour placing the direction of an observational project in the hands of one individual. Indeed I am inclined to believe that part of the secret of Terzaghi's success was his insistence on personal, full responsibility and authority on critical jobs. The project at Cape Kennedy, however, was carried out by a large organization with the aid of a board of three consultants. The exchange of ideas improved the solution, and the necessary close contact with the job proved not difficult to achieve.

The essential ingredient, without which all the others may lead to nothing, is the visualization of all possible eventualities and the preparation in advance of courses of action to meet whatever situation develops. Only if this is done can it be said that more than lip service has been paid to the use of the observational procedure.

\section{ACKNOWLEDGEMENTS}

The study of the Cape Kennedy causeway was made for the National Aeronautics and Space Administration, Kennedy Space Center, by the US Army Engineer Division, South Atlantic, and the US Army Engineer District, Canaveral. The members of the board of review were Dr Ralph E. Fadum, Dr W. J. Turnbull and the Author. 
The tunnelling in San Francisco was part of the programme of the Bay Area Rapid Transit District, of which Mr David G. Hammond was Director of Development and Operations. Mr W. A. Bugge was Project Director for Parsons Brinckerhoff-Tudor-Bechtel, General Engineering Consultants to the District.

The bedrock valley filled with glacial and waterborne deposits is the site of Lower Notch Dam of the Hydro-Electric Power Commission of Ontario. H. G. Acres and Co., Ltd are the consulting engineers, for whom Mr Robert J. Conlon is Head of the Geotechnical Department.

\section{REFERENCES}

Bjerrum, L., Casagrande, A., Peck, R. B. \& Skempton, A. W. (eds). (1960). From theory to practice in soil mechanics. Selections from the writings of Karl Terzaghi. New York: Wiley.

Casagrande, A. (1960). An unsolved problem of embankment stability on soft ground. Proc. 1st PanAmerican Conf. Soil Mech., Mexico 2, 721-746.

Graftio, H. (1936). Some features in connection with the foundations of Svir 3 hydro-electric power development. Proc. 1st Int. Conf. Soil Mech., Cambridge, Mass. 1, 284-290.

Peck, R. B. (1943). Earth-pressure measurements in open cuts, Chicago subway. Trans. Am. Soc. civ. Engys 108, 1008-1036.

Terzarri, K. (1961). Past and future of applied soil mechanics. J. Boston Soc. civ. Engrs 68, $110-139$.

TerzaghI, K. \& PECK, R. B. (1948). Soil mechanics in engineering practice. New York: Wiley.

White, E. E. (1958). Deep foundations in soft Chicago clay. Civ. Engng, Am. Soc. civ. Engrs $28,816-818$.

Wu, T. H. \& Berman, S. (1953). Earth pressure measurements in open cut: Contract D8, Chicago subway. Géotechnique 13 , No. $3,248-258$.

\section{VOTE OF THANKS}

In proposing the vote of thanks, Mr GLossop opened: "Hall and Knight, Liddell and Scott, and, of course, Terzaghi and Peck'-whatever else was necessary to make one a member of that small group of scientific and scholarly authors whose names were household words, one thing was certain: one must have written a very good book. To have done so was one of Professor Peck's achievements. It was a book known and used by all those interested in soil mechanics, and it would be known and used for many years to come.

Professor Peck was also an engineering scientist who had made important contributions to his subject, and to an audience who had just heard him lecture it was unnecessary to say that he was a practising civil engineer with very wide experience in the field on earthwork and foundation engineering. They were indeed fortunate to have heard him describe those fascinating case histories and also, perhaps even more, to have heard him philosophizing about the lessons he had learnt during a long and distinguished career.

In conclusion, he was sure they would all agree that Professor Peck's was an outstanding Rankine Lecture and, above all, that it had been an engineer's lecture. He thought that everyone would have learnt something useful from the Lecture, and had great pleasure in proposing a hearty vote of thanks to Professor Peck.

The vote of thanks was carried with acclamation. 